\title{
Lidocaína endovenosa para tratamiento de dolor refractario
}

\author{
Pizzi L. ${ }^{1}$, Nannini F. ${ }^{1}$ \\ 1 Hospital Luis C. Lagomaggiore, Mendoza, Argentina.
}

Introducción: El dolor refractario representa hoy en día una problemática difícil de resolver debido a sus componentes algésicos, variaciones de presentación y falta de respuesta a los diversos tratamientos actuales.

Método: Paciente de 37 años sin antecedentes patológicos, que ingresa por dolor de 1 mes de evolución en región dorsal derecha, con irradiación a hipocondrio y flanco derecho y epigastrio, de aparición insidiosa, intensidad 10/10, urente, que aumenta con movimientos corporales. Se diagnostica por métodos imagenológicos neoplasia pancreática con secundarismo hepático y pulmonar. Se instaura tratamiento analgésico por servicio de Medicina Paliativa con Amitriptilina, Pregabalina, Metadona y AINEs en dosis crecientes, respetando los tiempos de efectos terapéuticos, sin mejoría clínica durante dos semanas de internación. Ante la urgencia de la situación, se interconsulta a nuestro servicio. Debido a la imposibilidad de realizar en ese momento técnica de analgesia regional, se decide instaurar bomba de infusión continua endovenosa de Lidocaína con dosis de carga de $1 \mathrm{mg} / \mathrm{kg}$ y matenimiento de $1 \mathrm{mg} / \mathrm{kg} / \mathrm{h}$.

Resultados: Se evalúa dolor mediante EVA a las 2 y 6 h, hallándose 6/10 y 3/10 respectivamente, con notable mejoría psico-orgánica y sueño reparador completo.

Conclusiones: Debido a los diversos mecanismos de acción analgésicos, antihiperalgesicos, antiinflamatorios centrales y periféricos y antineoplásicos de la Lidocaína en infusión continua, resultó efectiva para el manejo de dolor refractario siendo una estrategia efectiva y segura en la urgencia.

https://doi.org/10.25237/congresoclasa2019.13 